\title{
Rupert Pegram: Thirteen years of hell in paradise
}

\author{
Trafford Publishing, USA, 2011, (ISBN paperback edition 978-1-4296-4453-6) US\$25, \\ available from www.trafford.com
}

\author{
Alan R. Walker \\ Accepted: 31 January 2011 /Published online: 5 March 2011 \\ (C) Springer Science+Business Media B.V. 2011
}

The Caribbean Amblyomma Programme aimed to eradicate the tropical bont tick, Ambylomma variegatum, from all of the 18 islands and states of the Caribbean that were infested in the 1990s. This tick would be truly banished from the Caribbean and the threat it posed to cattle industry in the tropical Americas removed. Indigenous to Africa, about 1750 , this tick got into Guadeloupe on a shipment of cattle from Senegal. It is a severe pest in its own right, causing substantial loss of gain in live weight and milk yield. The potentially fatal Ehrlichia ruminantium is commonly transmitted by the tick to ruminants. By suppressing the immunity of cattle, skin infections with Dermatophilus congolensis are aggravated to a level that can be fatal. For a nation state to become infested is a disaster for livestock owners, hence the mobilisation of a programme supported by at least 11 aid organisations to fund and implement the eradication.

This complexity was the main source of the troubles for the author of this personal and informal account, and a reason why it failed in its overall aim. Eradication was confirmed in just four islands by the time funding stopped in 2006. The other reason why it failed was that during the 12-year period of planning before the CAP (and before Dr Pegram's involvement), there was a severe incongruity between the ideas and experience of the planners on how to run tick eradication programmes in the USA, southern

\footnotetext{
A. R. Walker $(\bowtie)$

Royal (Dick) School of Veterinary Studies,

Summerhall Place,

EH9 1QH Scotland, UK

e-mail: alanw@staffmail.ed.ac.uk
}

Africa and Australia, contrasted with the farming realities of the Caribbean. That was compounded by the toughness and longevity of $A$. variegatum compared to tick species successfully eradicated elsewhere. On most of the islands, livestock rearing is small scale, with cattle typically kept tethered, sheep and goats free ranging on areas that may contain many feral donkeys, and profits insufficient for adequate veterinary care. These animals were often obstreperous, thus impossible to treat in dip tanks or spray races, and some of the cattle are even difficult to approach for treatment with pour-on acaricide. The plan and funds for labour of the treatment teams were eightfold too low. The treatments should have lasted four, not the planned 2 years. The feral animals were inaccessible but sufficiently good hosts of the tick to maintain stubborn residual foci. As the author put it in his introduction: 'To even the most sunnily-disposed observer, the CAP must appear to be one of the most controversial and ill-conceived animal health interventions ever embarked upon by an international community.'

This book is essential for any veterinary or medical eradicator, and best read together with the account by historian Claire Strom of the eventually successful eradication of Boophilus ticks from the USA. Similar gross lack of social knowledge made the early years of that programme a dangerous farce, but that was little discussed in the formal literature. It takes an academic historian and a tick ecologist writing in a private capacity to make this crucial point about intimate knowledge of local field conditions and pest biology. Let us hope that the increased availability of publishing methods and distribution networks now available electronically to such authors will sustain and spread these old understandings that are so sadly ignored. 